\title{
CHARACTERISATION OF A HIGHLY SYMMETRICAL MINIATURE CAPACITIVE TRIAXIAL ACCELEROMETER
}

\author{
J.C. Lötters, W. Olthuis, P.H. Veltink, P. Bergveld \\ MESA Research Institute, University of Twente \\ P.O. Box 217, $7500 \mathrm{AE}$ Enschede, The Netherlands \\ Phone: +31-53-4892755; Fax: +31-53-4892287; e-mail: j.c.lotters@el.utwente.nl
}

\section{SUMMARY}

\begin{abstract}
A highly symmetrical cubic capacitive triaxial accelerometer for biomedical applications has been designed, realised and tested. The sensors are available in two outer dimensions, namely $2 \times 2 \times 2$ and $5 \times 5 \times 5 \mathrm{~mm}^{3}$. The devices are mounted on a standard IC package for easy testing. Features of the sensor are a highly symmetrical cubic structure, capacitive coupling of the high frequency input voltage to the seismic mass and the use of the polymers polydimethylsiloxane (PDMS) as spring material between the capacitor plates and the mass and polyimide (PI) as flexible interconnection layer between the capacitor plates. The sensor structure and its basic operating principle, its mathematical mass-spring-damper model and the necessary cleanroom technology are described. The measurement results show a sensitivity of $\sim 0.15 \mathrm{~V} /\left(\mathrm{m} / \mathrm{s}^{2}\right)$ with a corresponding resolution of $0.01 \mathrm{~m} / \mathrm{s}^{2}$, an off-axis sensitivity of $<5 \%$, a good linearity in the output voltage for accelerations up to at least $50 \mathrm{~m} / \mathrm{s}^{2}$ and a bandwidth of DC $500 \mathrm{~Hz}$.
\end{abstract}

Keywords: triaxial accelerometer, capacitive sensor, threedimensional structure

\section{INTRODUCTION}

There is a need for very small triaxial accelerometers in the biomedical field. The accelerometers should meet the following specifications: amplitude range $\pm 50 \mathrm{~m} / \mathrm{s}^{2}$, resolution $0.01 \mathrm{~m} / \mathrm{s}^{2}$, bandwidth DC $-50 \mathrm{~Hz}$, off-axis sensitivity $<5 \%$, dimensions $\sim 2 \times 2 \times 2 \mathrm{~mm}^{3}$ and power consumption $<1 \mathrm{~mW}$.

Up to now, triaxial accelerometers presented in the literature $[1,2,3]$ have a lack of symmetry and therefore show a large offaxis sensitivity from $5 \%$ up to $21 \%$ [1]. The sensor proposed in this paper has a highly symmetrical configuration, consisting of a central cubic seismic mass surrounded by capacitors, which ideally should not result in any off-axis sensitivity. Furthermore, due to the high degree of symmetry and differential measuring, common mode interferences as introduced by temperature fluctuations, electric and magnetic fields, humidity and other disturbing effects should be rejected. In this paper, the sensor structure and basic operating principle, its theoretical mass-spring-damper model, cleanroom technology and measurement results are described.

\section{THEORY}

\section{Sensor Structure And Basic Operating Principle}

The basic structure of the sensor consists of a central cubic tungsten seismic mass enclosed by fixed capacitor plates (figure 1a). The mass is suspended to the fixed capacitor plates by springs made of polydimethylsiloxane (PDMS).

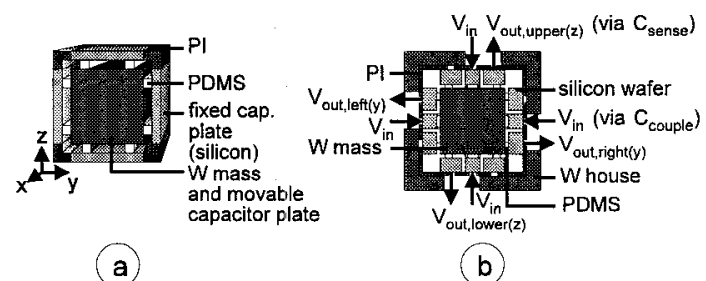

Figure 1. Basic structure of the triaxial accelerometer, cross-sectional (a) $3 D$ view, (b) $2 D$ view

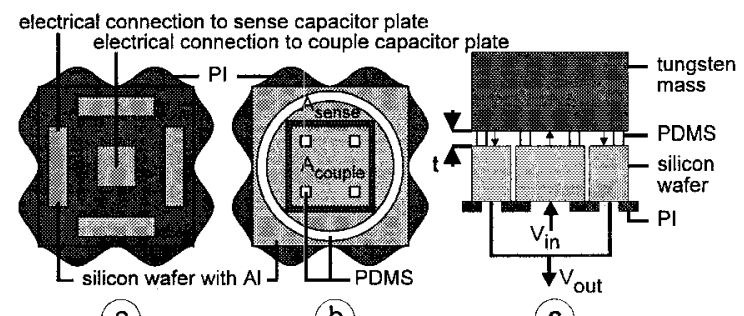

(a)

(b)

(c)

Figure 2. (a) Rear view and (b) front view of the two separate fixed capacitor plates confronting each side of the mass; (c) two-dimensional cross-sectional view of a part of the basic structure of the symmetrical cubic triaxial accelerometer

There are two separate fixed capacitor plates confronting each side of the mass (figures $1 \mathrm{~b}, 2 \mathrm{~b}$ ). The inner capacitor $C_{\text {couple }}$ $[\mathrm{F}]$ is used to capacitively connect the supply voltage $V_{\text {in }}[\mathrm{V}]$ to the seismic mass and the outer capacitor $C_{\text {sense }}[\mathrm{F}]$ is used to sense the applied accelerations (figures $1 \mathrm{~b}, 2 \mathrm{c}$ ). The nominal distance $t_{\text {side }}[\mathrm{m}]$ between the capacitor plates and the central mass is determined by the thickness of the PDMS structure. When an acceleration is applied, the mass moves a distance $\Delta t$ [m] with respect to the fixed outer capacitor plates, resulting in a corresponding capacitance change $\Delta C_{\text {sense. }}$. When the triaxial accelerometer is connected to a differential capacitance to voltage converter (CVC) [4], the output voltage $V_{\text {out }, z}[\mathrm{~V}]$ due to an applied acceleration $a_{z}\left[\mathrm{~m} / \mathrm{s}^{2}\right]$ is [5]

$$
\begin{aligned}
& V_{\text {out }, z}= \\
& =H_{\text {ina }} \hat{V}_{\text {in }}\left[\frac{C_{\text {couple,total }}}{C_{\text {couple }, \text { toral }}+C_{\text {sense }, \text { total }}} \frac{C_{\text {sense }, z, 0}}{C_{f}}\right] \frac{2 m a_{z}}{k_{\text {toral }, z} \cdot t_{z}}
\end{aligned}
$$


with $H_{\text {ina }}$ the gain of the instrumentation amplifier, $\hat{V}_{\text {in }}[\mathrm{V}]$ the amplitude of the supply voltage, $C_{\text {couple, total }}=6 C_{\text {couple }}$, $C_{\text {sense, total }}=6 C_{\text {sense, }}, C_{\text {sense, } z, 0}[\mathrm{~F}]$ the nominal sense capacitance in the z-direction, $C_{f}[\mathrm{~F}]$ the feedback capacitor of the CVC, $m[\mathrm{~kg}]$ the seismic mass and $k_{\text {total }, z}[\mathrm{~N} / \mathrm{m}]$ the spring constant in the z-axis. When $C_{f}$ is adjusted such that the term between brackets equals 0.5 , equation (1) can be simplified:

$V_{\text {out }, z}=H_{\text {ina }} \hat{V}_{\text {in }} \frac{m a_{z}}{k_{\text {total }, z} \cdot t_{z}}$

Corresponding equations can be derived for the output voltage in the $\mathrm{x}$ and $\mathrm{y}$-direction.

\section{Mass-Spring-Damper System}

In the frequency domain, the output voltage $V_{\text {out }}(j \omega)$ [V] is not only dependent on the applied acceleration but also on the mass $m[\mathrm{~kg}]$, spring constant $k_{\text {total }}[\mathrm{N} / \mathrm{m}]$ and damping constant $b_{\text {total }}[\mathrm{Ns} / \mathrm{m}]$ of the triaxial accelerometer. In the zdirection, $V_{o u t, z}(j \omega)$ can be equated with

$$
V_{\text {out }, z}(j \omega)=V_{\text {out }, z} \cdot \frac{1}{\left(\frac{j \omega}{\omega_{0, z}}\right)^{2}+\frac{\beta_{z} j \omega}{\omega_{0, z}}+1}
$$

with $\omega_{0, z}=\sqrt{\frac{k_{\text {total }, z}}{m}}$

the resonance frequency $[\mathrm{rad} / \mathrm{s}]$ of the system

and $\beta_{z}=\frac{1}{Q_{z}}=\frac{b_{\text {total }, z}}{\sqrt{k_{\text {total }, z} \cdot m}}$

the damping coefficient, which is the reciprocal of the quality factor $Q_{z}$, of the system.

The mass $m[\mathrm{~kg}]$ is known by weighing, the total spring constant in e.g. the z-direction can be calculated to be [6]

$k_{\text {total }, z}=10 . A_{P D M S} G / t_{z}$

with $A_{P D M S}\left[\mathrm{~m}^{2}\right]$ the area of the PDMS on one side and $G[\mathrm{~Pa}]$ the shear elastic modulus of the PDMS.

There are many damping mechanisms. The most important damping factors in this application are:

(I) air streaming resistance, also called squeeze film damping, due to streaming of air in and out of the capacitor, with damping constant $b_{A S R}$ at the resonance frequency $\omega_{0}$ derived from equations found in $[7,8]$

$b_{A S R}=\frac{12 v A^{2}}{\pi^{3} t_{\text {side }}{ }^{3}}$

with $v=17.6^{*} 10^{-6}$ the viscosity of air [Pa.s] and $A$ the area of the capacitor plates $\left[\mathrm{m}^{2}\right]$.
(II) damping of PDMS, due to its loss tangent, with damping coefficient $b_{P D M S}$ [7]

$b_{\text {PDMS }}=\tan \delta \cdot \sqrt{k_{\text {total }} \cdot m}$

with $\tan \delta$ the loss tangent of the PDMS.

The total damping constant in one direction can now be equated with

$b_{\text {total }, z}=2 b_{A S R, z}+6 b_{P D M S, z}$

\section{EXPERIMENTAL}

Cleanroom technology and assembly procedure

Objective of the cleanroom technology is the realisation of a foldable cross structure, as shown in figure 4 . In the assembly procedure, the cross structure is folded around the seismic mass [5]. The process flow of the cleanroom technology is shown in figure 3 and was extensively described in [5]. The only thing that has changed is the protective layer for the PDMS structures. In [5], the PDMS was covered with a chromium layer, but due to cracks in the chromium layer the PDMS structures were removed during RIE etching. At present, the PDMS is covered with a PI layer of $50 \mu \mathrm{m}$ thick which is not baked (figure $3 \mathrm{f}$ ). After the RIE etching, when the foldable crosses are etched free, the unbaked PI was removed by putting the crosses in boiling water in an ultrasonic cleaner. The protective aluminium and chromium layers were removed with aluminium and chromium etchant, respectively, and the structures were ready to be assembled (figures $3 \mathrm{~h}$ and 4). All dimensions, material properties and CVC data are shown in table I. After assembly, the devices look as is shown in fig. 5.

Table I. Dimensions, material properties and CVC data

\begin{tabular}{lll}
\hline sensor size: & $5 \times 5 \times 5 \mathrm{~mm}^{3}$ & $2 \times 2 \times 2 \mathrm{~mm}^{3}$ \\
seismic mass & $m=520 \mathrm{mg}$ & $19 \mathrm{mg}$ \\
& edge $e=3 \mathrm{~mm}$ & $1 \mathrm{~mm}$ \\
PDMS & $A_{\text {PDMS, sense }}: 4.10^{-7} \mathrm{~m}^{2}$ & $1.10^{-7} \mathrm{~m}^{2}$ \\
& $A_{\text {PDMS, couple: }}: 4.10^{-8} \mathrm{~m}^{2}$ & - \\
& $G=250 \mathrm{kPa}$ & $250 \mathrm{kPa}$ \\
& $\varepsilon_{r}=2.5$ & 2.5 \\
& tan $<0.001$ & $<0.001$ \\
& $t \cong 10 \mu \mathrm{m}$ & $\cong 2.5 \mu \mathrm{m}$ \\
capacitor/side & outer length $l=3 \mathrm{~mm}^{2}$ & $1 \mathrm{~mm}$ \\
& $A_{\text {sense }}=6.75 .10^{-6} \mathrm{~m}^{2}$ & $1.10^{-6} \mathrm{~m}^{2}$ \\
& $A_{\text {couple }}=2.25 .10^{-6} \mathrm{~m}^{2}$ & - \\
& $C_{\text {sense, side, } 0} \cong 5 \mathrm{pF}$ & $\sim 4 \mathrm{pF}$ \\
& $C_{\text {couple, side, } 0 \cong 1.7 \mathrm{pF}}$ & - \\
& $C_{f}=4 . .10 \mathrm{pF}$ & $4 . .10 \mathrm{pF}$ \\
& $H_{\text {ina }}=100$ & 100 \\
& $\hat{V_{\text {in }}}=5 \mathrm{~V}$ & $10 \mathrm{~V}$ \\
& noise DC-50 Hz: $1.5 \mathrm{mV}$ & $1.5 \mathrm{mV}$ \\
\hline
\end{tabular}


(a)

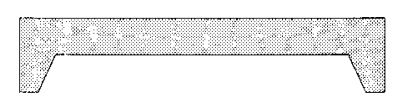

(b)

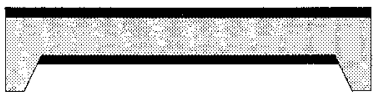

(c)

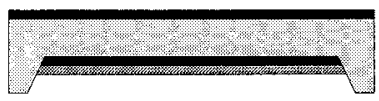

(d)
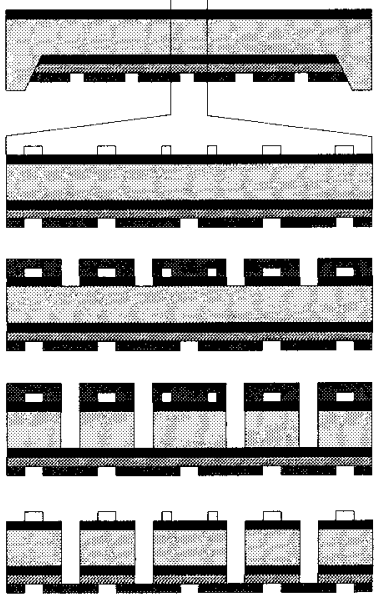

Figure 3. Process steps of the triaxial accelerometer: from silicon wafer to foldable cross structure

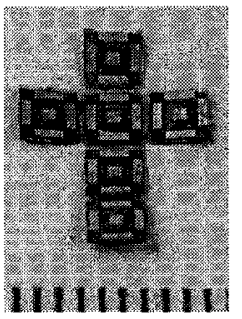

(a)

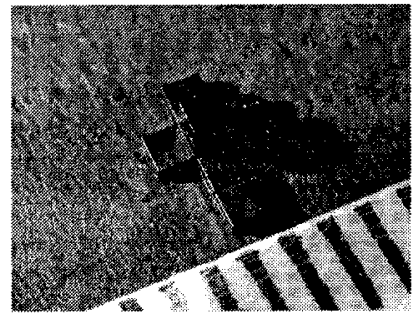

(b)
Figure 4. (a) Big and (b) small foldable cross structure on a mm-scale

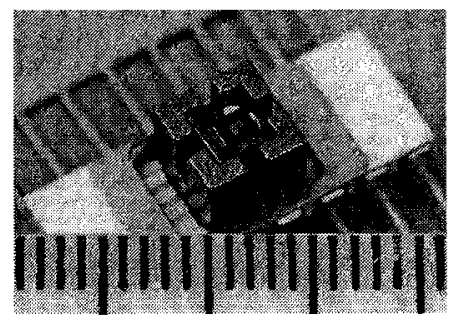

(a)

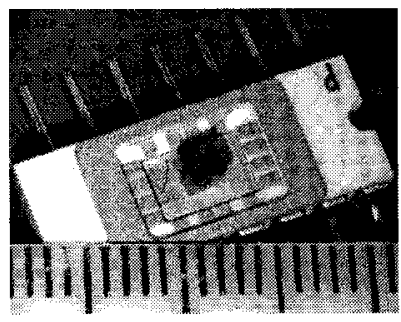

(b)
Figure 5. Triaxial accelerometers with a size of (a) $5 \times 5 \times 5 \mathrm{~mm}^{3}$ and (b) $2 \times 2 \times 2 \mathrm{~mm}^{3}$ in a tungsten housing on an IC package. Bond wires are attached via slits in the walls of the housing

\section{Measurement protocol}

The devices were statically tested by turning their sensitive axes with respect to gravity and dynamically tested by applying known accelerations (reference accelerometer Piezotronics ICP 301A10) with a shaker unit (Gearing and Watson GWV20).

\section{RESULTS AND DISCUSSION}

When the data of table I is substituted in the equations (1) through (9), the behaviour of the sensor can be theoretically predicted. The results of both the calculations and the measurements are shown in table II. It should be noted that the small sensor B3 was realised using a more complicated assembly procedure in which a gold bond wire, instead of the six couple capacitors in parallel, was used to connect the supply voltage to the seismic mass [9]. However, small sensors constructed as described in this paper will be available in due time.

The static sensitivity of the devices as shown in figure 5 was determined by turning their sensitive axes with respect to gravity. As can be seen in table II, the measured and calculated sensitivity show a reasonably good correspondence. Differences in calculated sensitivity between the axes in one sensor can be explained by unequal height of the PDMS structures due to compression of the PDMS structures during assembly. When the sensitivity in a certain direction is less than calculated, as in B3 y and D2_z, this is probably caused by compression of the PDMS layers in that direction. When the sensitivity in a certain direction is higher than calculated, as in $\mathrm{D} 2 \mathrm{x}$ and D3 $\mathrm{z}$, the higher sensitivity is probably due to a bad mechanical connection between some of the PDMS structures and the seismic mass [6].

The resolution of the sensor is dependent on the rms noise level of the CVC which was found to be $1.5 \mathrm{mV}$ in the frequency range DC $-50 \mathrm{~Hz}$ [4]. So, given the sensitivity and the noise level of the CVC, the resolution can be calculated. The result is shown in table II.

The linearity of the devices B3 and D3 is shown in figure 6 . The output voltage of all axes increases linearly with the applied acceleration, up to at least $50 \mathrm{~m} / \mathrm{s}^{2}$.

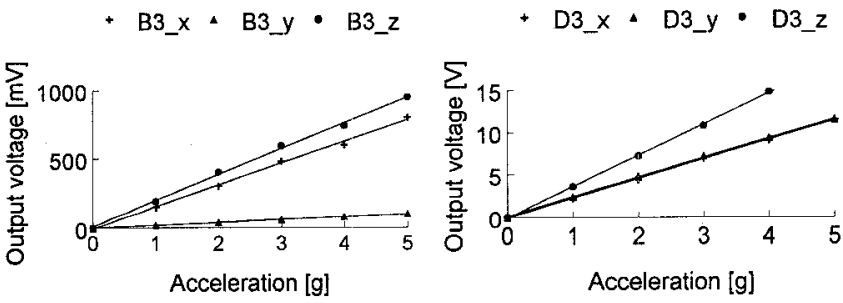

Figure 6. Linearity of sensors B3 and D3: measured output voltage per axis versus the applied acceleration 
4B1.03

As can be seen in table II there is a large mismatch between the calculated and measured bandwidth. This mismatch can be explained in two ways [10]: the first explanation is a bad adhesion between some of the PDMS layers and the seismic mass; the second explanation is a local deformation of some of the PDMS structures due to compressive stress causing them to be much stiffer than in the uncompressed case. Both phenomena cause a much larger damping and therefore a smaller bandwidth than expected.

\section{CONCLUSIONS}

A highly symmetrical miniature cubic capacitive triaxial accelerometer has been designed, realised and tested. The outer dimensions of the sensor are $2 \times 2 \times 2 \mathrm{~mm}^{3}$ and $5 \times 5 \times 5 \mathrm{~mm}^{3}$. The device is put upon a standard IC package for easy testing. The mathematical mass-spring-damper model, technology and measurements results of the sensor were described. The measurement results show a sensitivity of $\sim 0.15 \mathrm{~V} /\left(\mathrm{m} / \mathrm{s}^{2}\right)$ with a corresponding resolution of $0.01 \mathrm{~m} / \mathrm{s}^{2}$, an off-axis sensitivity of $<5 \%$, a good linearity in the output voltage for accelerations up to at least $50 \mathrm{~m} / \mathrm{s}^{2}$ and a bandwidth of DC $500 \mathrm{~Hz}$, thus meeting all specifications. A bandwidth lower than expected can be explained by both a bad mechanical connection and a high compressive stress between some of the PDMS structures and the tungsten seismic mass.

\section{ACKNOWLEDGMENTS}

The authors would like to thank Mr. J.G. Bomer, Mr. A.J. Verloop and Mr. Ed A. Droog for their assistance in device preparation and electronic circuitry, Dr. C. Blom for his helpful comments on rheological and damping questions and the Dutch Technology Foundation (STW) for its financial support.

\section{REFERENCES}

[1] K. Jono, M. Hashimoto, M. Esashi, Electrostatic servo system for multi-axis accelerometers, Proceeding IEEE MEMS, 1994, pp. 251-256
[2] T. Mineta, S. Kobayashi, Y. Watanabe, S. Kanauchi, I. Nakagawa, E. Suganuma, M. Esashi, Three-axis capacitive accelerometers with uniform axial sensitivities, Proceedings Transducers'95, Stockholm, Sweden, 1995, pp. 554-557

[3] K. Okada, Tri-axial piezoresistive accelerometer, Technical digest of the $11^{\text {th }}$ sensor symposium, 1992 , pp. 245-248

[4] J.C. Lötters, W. Olthuis, P.H. Veltink, P. Bergveld, $A$ sensitive differential capacitance to voltage converter for sensor applications, submitted to IEEE Instrumentation and Measurement techniques

[5] J.C. Lötters, W. Olthuis, P.H. Veltink, P. Bergveld, Theory, technology and assembly of a highly symmetrical capacitive triaxial accelerometer, proceedings of IEEE MEMS'97, 26-30 January 1997, Nagoya, Japan, pp. 31-36

[6] J.C. Lötters, W. Olthuis, P.H. Veltink, P. Bergveld, Polydimethylsiloxane, a photocurable rubberelastic polymer used as spring material in micromechanical sensors, Journal of Microsystem Technologies, 3 (1997), pp. 64-67

[7] R.W. Whorlow, Rheological techniques, John Wiley \& sons, New York, 1980

[8] M.K. Andrews, I.M. Harris, G.C. Turner, $A$ comparison of squeeze-film theory with measurements on a microstructure, Sensors and actuators A36, 1993, pp. $219-226$

[9] J.C. Lötters, W. Olthuis, P.H. Veltink, P. Bergveld, Design, realization and characterization of $a$ symmetrical triaxial capacitive accelerometer for medical applications, accepted for publication in Sensors \& Actuators, 1997

[10] C. Blom, Experimental study of linear viscoelastic properties of some dispersions, Ph.D. thesis, University of Twente, 1985

Table II. Measured and calculated values of important parameters of three triaxial accelerometers

\begin{tabular}{|c|c|c|c|c|c|c|c|c|}
\hline \multirow{2}{*}{$\begin{array}{l}\text { Device } \\
\text { axis }\end{array}$} & \multirow{2}{*}{$\begin{array}{l}\text { Dimens. } \\
{\left[\mathrm{mm}^{3}\right]}\end{array}$} & \multicolumn{2}{|c|}{ Sensitivity $\left[\mathrm{V} /\left(\mathrm{m} / \mathrm{s}^{2}\right)\right]$} & \multirow{2}{*}{$\begin{array}{l}\text { Resolution } \\
{\left[\mathrm{m} / \mathrm{s}^{2}\right]}\end{array}$} & \multirow{2}{*}{$\begin{array}{l}\text { Linearity } \\
\text { range }\left[\mathrm{m} / \mathrm{s}^{2}\right]\end{array}$} & \multirow{2}{*}{$\begin{array}{l}\text { Off-axis } \\
\text { sens. [\%] }\end{array}$} & \multicolumn{2}{|c|}{ Bandwidth [kHz] } \\
\hline & & Calc. & Meas. & & & & Calc. & Meas. \\
\hline & $2 \times 2 \times 2$ & 0.16 & 0.15 & 0.01 & $> \pm 50$ & 3 & 10 & 3 \\
\hline B3 $y$ & & 0.16 & 0.02 & 0.08 & $> \pm 50$ & 3 & 10 & 3 \\
\hline B3_z & & 0.16 & 0.19 & $<0.01$ & $> \pm 50$ & 2 & 10 & 3 \\
\hline $\mathrm{D} 2-\mathrm{x}$ & $5 \times 5 \times 5$ & 0.18 & 0.35 & $<0.01$ & $> \pm 50$ & 2 & 2 & 0.5 \\
\hline $\mathrm{D} 2 \_\mathrm{y}$ & & 0.28 & 0.27 & $<0.01$ & $> \pm 50$ & 1 & 2 & 0.5 \\
\hline $\mathrm{D} 2 \mathrm{z}$ & & 0.23 & 0.15 & $<0.01$ & $> \pm 50$ & 3 & 2 & 0.5 \\
\hline D3 $x$ & $5 \times 5 \times 5$ & 0.24 & 0.22 & $<0.01$ & $> \pm 50$ & 5 & 3 & 0.5 \\
\hline D3 y & & 0.24 & 0.24 & $<0.01$ & $> \pm 50$ & 3 & 3 & 0.5 \\
\hline D3 $z$ & & 0.24 & 0.36 & $<0.01$ & $> \pm 50$ & 4 & 3 & 0.5 \\
\hline
\end{tabular}

